\title{
B-Type Natriuretic Peptide as a Marker for Cardiac Dysfunction in Anthracycline-Treated Children
}

\author{
Sanjeev Aggarwal, MD, Michael D. Pettersen, MD, Kanta Bhambhani, MD, \\ Joellyn Gurczynski, Ronald Thomas, PhD, and Thomas L'Ecuyer, MD*
}

\begin{abstract}
Background. Anthracyclines (AC) are useful antineoplastic agents, whose utility is limited by progressive cardiotoxicity. Our purpose was to evaluate plasma B-type natriuretic peptide (BNP), as a screening test for detecting late cardiac dysfunction in AC-treated children and to determine the prevalence of late cardiac dysfunction at low cumulative AC doses. Materials and Methods. This was a prospective study in which patients who had completed AC therapy at least 1 year earlier, underwent a detailed echocardiogram and a simultaneous BNP level. Cardiac dysfunction was defined as any one of the following: shortening fraction $(\mathrm{FS})<29 \%$, rate corrected velocity of circumferential fiber shortening $(\mathrm{VCFC})<0.9 \mathrm{c} \cdot \mathrm{sec}^{-1}$, end systolic wall stress (ESWS) $>60 \mathrm{~g} \cdot \mathrm{cm}^{-2}$, abnormal VCFc: ESWS ratio or decreased mitral inflow velocity (E/A) ratios, compared to age-specific norms. Results. The cohort $(n=63)$ included 37 males
\end{abstract}

with a median age of 13.1 years (range, 6.5-26.5 years). Cardiac dysfunction was found in $26(41 \%)$ patients and in $40 \%$ of patients who received cumulative doses $<150 \mathrm{mg} \cdot \mathrm{m}^{-2}$. ESWS was the most common abnormality. Mean BNP levels in the subset with abnormal function were significantly higher than the normal group $\left(23.4 \pm 25.3\right.$ vs. $\left.14.2 \pm 8.9 \mathrm{pg} \cdot \mathrm{ml}^{-1}, P=0.02\right)$. Conclusions. Plasma BNP was significantly elevated in AC-treated patients with late cardiac dysfunction, although there was considerable overlap of levels between groups with and without cardiac dysfunction. BNP may need further evaluation as a serial index of cardiac function in this population. Cardiac dysfunction was observed in a significant proportion of patients, even at low cumulative AC doses. Pediatr Blood Cancer 2007;49:812-816. 두 2006 Wiley-Liss, Inc.

Key words: Anthracyclines-induced cardiotoxicity; BNP

\section{INTRODUCTION}

Anthracyclines (AC) are highly effective chemotherapeutic agents, whose full clinical potential is limited by cardiac toxicity (ACT) [1-4]. ACT is progressive, may become manifested many years after the completion of treatment and occurs at variable threshold doses [5-8]. The evolution of AC-induced subclinical cardiac dysfunction is not clearly understood and other than vigilant monitoring, there are no explicit guidelines for its management [6,9-11]. Therefore, each AC recipient requires monitoring for cardiotoxicity for a long period of time, the duration of which is not known.

Monitoring for ACT is most simply accomplished by echocardiographic measures, including fractional shortening (FS) and ejection fraction (EF) [12]. However, these measures are dependent on ventricular loading conditions and lack sensitivity for detecting ACT $[13,14]$. FS alone is reduced in $28 \%$ of AC-treated patients, whereas $57 \%$ have an abnormal left ventricular afterload, as measured by end systolic wall stress (ESWS) or contractility measured by the stress velocity index (SVI) [3]. These more sophisticated parameters are technically difficult to obtain in children. An objective, easily obtained biomarker of ventricular function would greatly add to the clinical care of AC-treated patients.

Plasma B-type natriuretic peptide (BNP) is a cardiac hormone secreted from the ventricles, in response to ventricular volume and pressure overload [15]. Levels increase in proportion to the severity of congestive heart failure (CHF) in adults and children [16-18]. In the pediatric age group, values of BNP of $7 \pm 5.9$ and $10.1 \pm 8.6 \mathrm{pg} \cdot \mathrm{ml}^{-1}$ have been reported in healthy boys and girls, respectively [19]. Comparable BNP levels are noted in neonates after closure of patent ductus arteriosus and children with cardiomyopathy, without clinical signs of heart failure [20,21]. The role of BNP in screening for late onset ACT remains to be elucidated. One previous study found plasma BNP to be significantly elevated in patients with a reduction of FS or EF [22].
The rationale for our study was that plasma BNP may be elevated in AC-treated patients with late cardiac dysfunction. Our primary objective was to evaluate plasma BNP as a screening test for detecting late onset $\mathrm{AC}$-induced cardiac dysfunction, in comparison to detailed sensitive indices, not ordinarily available from a clinical echo.

Since the mid 1990s, cumulative AC doses have been empirically limited to below $550 \mathrm{mg} \cdot \mathrm{m}^{-2}$ due to the high incidence of clinically important cardiotoxicity observed above this dose [23]. More recently, a further dose reduction to below $250 \mathrm{mg} \cdot \mathrm{m}^{-2}$ has been suggested to reduce the incidence of ACT [9]. Limited information is available about the impact of progressive AC dose curtailment on the incidence of late cardiac dysfunction. Our secondary aim, therefore, was to define the prevalence of cardiac dysfunction using load-independent echocardiographic measures in a cohort of patients treated with low cumulative AC doses.

\section{MATERIALS AND METHODS}

This prospective non-interventional study was conducted at Children's Hospital of Michigan, after approval by the Human Investigation Committee. Patients were enrolled between October 2003 and June 2004 after obtaining written informed consent from parents or guardians.

\section{Selection Criteria}

Patients who had completed AC chemotherapy at least 1 year prior to enrollment were included. Patients with congenital heart

Department of Pediatrics, Wayne State University, Children's Hospital of Michigan, Michigan

*Correspondence to: Thomas L'Ecuyer, MD, Division of Cardiology, Children's Hospital of Michigan, 3901 Beaubien Blvd, Detroit, MI 48201. E-mail: thlecuye@med.wayne.edu

Received 30 May 2006; Accepted 23 October 2006 
disease, cardiomyopathy prior to initiation of chemotherapy, renal failure (serum creatinine more than twice the age-specific norms), patients who received mediastinal radiation, were pregnant or critically ill, were excluded. Each patient underwent an echocardiogram and simultaneous blood draw for BNP assay for research purposes.

\section{Clinical Data}

Clinical data obtained for each subject included demographics, clinical diagnosis, the cumulative dose of $\mathrm{AC}$ received, time elapsed since the completion of AC therapy, and cardiac symptoms.

\section{Echocardiography}

Echocardiograms were performed using a Phillips Sonos 5500 ultrasound machine. Each patient underwent M mode, 2D and Doppler echocardiogram with simultaneous recording of carotid pulse tracing, electrocardiogram, phonocardiogram, and blood pressure. Echo parameters were selected to measure (a) left ventricular systolic function (shortening fraction FS, ejection fraction $\mathrm{EF}$ and rate corrected mean velocity of circumferential fiber shortening VCFc), (b) afterload (end systolic wall stress ESWS), (c) contractility (Stress velocity index SVI), and (d) left ventricular diastolic function (peak $\mathrm{E}$ and $\mathrm{A}$ velocities and their ratio). FS and EF were calculated as described [24,25]. Shortening fraction below $29 \%$ and EF less than $64 \%$ were considered abnormal $[12,25]$. VCFc was obtained by the method described by Colan et al. $[3,26]$ and considered abnormal below $0.90 \mathrm{c} \cdot \mathrm{sec}^{-1}$. ESWS was calculated by the method described by Grossman et al. and considered abnormal above $60 \mathrm{~g} \cdot \mathrm{cm}^{-2}[3,27]$. The SVI or the relationship between $\mathrm{VCF}$ and ESWS were measured by the method described by Colan et al. [26]. A VCFc value two standard deviations below normal in relation to ESWS was considered to represent abnormal contractility [26,28]. E/A ratio was obtained by pulse Doppler at the mitral valve inflow and compared to established normal values [29]. All echocardiograms were read by a single cardiologist (MP) who was blinded to patient data and results of the BNP assay.

Abnormal cardiac function was defined by any one of the following criteria: FS $<29 \%$; VCFc $<0.90 \mathrm{c} \cdot \mathrm{sec}^{-1}$; ESWS $>60 \mathrm{~g} \cdot \mathrm{cm}^{-2}$; abnormal VCFc: ESWS ratio; or decreased E/A ratio, based on age-specific normal values. EF was not included in our preset criteria of cardiac dysfunction due to inherent fallacies in its echocardiographic measurement in the pediatric age group [25].

\section{Plasma BNP Assay}

Blood samples $(3 \mathrm{ml}$ ) were collected in K-EDTA tubes within 3 hours of the echocardiogram and were centrifuged immediately at $3,500 \mathrm{rpm}$ for $10 \mathrm{~min}$. Platelet-free plasma was stored at $-20^{\circ} \mathrm{C}$. BNP assay was performed using the Triage BNP kit (Biosite Diagnostic, San Diego, California).

\section{Statistical Analysis}

Statistical analyses were performed using SPSS (version 12) software. Sample size was predetermined using a two-tailed test with a significance (alpha) set at 0.05 to achieve a power of $81 \%$, based on the assumption that the BNP would be higher in patients with abnormal heart function on echocardiogram by $20 \mathrm{pg} \cdot \mathrm{dl}^{-1}$ (corresponding to means \pm SD of $9 \pm 14.8$ and $29 \pm 31.2$, respectively, based on a prior study) [22]. The number of patients required to achieve a power of $80 \%$ was 23 in each group. Since 50-60\% of pediatric patients who receive AC have abnormal contractility and/or afterload, we enrolled 63 patients with an expectation of two nearly equal subsets - those with and without cardiac dysfunction [3]. Data were expressed as mean $\pm \mathrm{SD}$ for continuous variables and as a number (percentage) for categorical variables. The two groups were compared for continuous variables using the Student $t$-test for independent samples [30]. Box and whisker plots of BNP levels were used to show the distribution in the subgroups based on cardiac function. Statistical significance was set as $P<0.05$. All hypotheses were two tailed.

\section{RESULTS}

\section{Subject Characteristics}

Eighty patients were identified from the echo database in the cardiology clinic. Two could not be traced and 15 patients refused consent. Sixty-three patients were enrolled in the study including 37 (59\%) males and $26(41 \%)$ females. The median age at enrollment was 13.1 years (range, 6.5-26.5) and the median interval since completion of AC treatment was 3.8 years (range, 1.1-17.5). The clinical diagnoses included acute lymphocytic leukemia in 29 (46\%), Wilms tumor in $12(19 \%)$, osteosarcoma in $12(19 \%)$, and lymphoma in 10 patients $(16 \%)$. Five patients were on cardiac medications (ACE inhibitors and digoxin) for ventricular dysfunction, of whom three were symptomatic with CHF, while two had asymptomatic abnormal LV function. None of our patients had a history of acute cardiac failure immediately following an AC dose. The median cumulative dose of $\mathrm{AC}$ received was $165 \mathrm{mg} \cdot \mathrm{m}^{-2}$ (range, 45-520; mean $160 \mathrm{mg} \cdot \mathrm{m}^{-2}$ ). The cumulative AC dose received was less than $150 \mathrm{mg} \cdot \mathrm{m}^{-2}$ in $29(46 \%)$ patients, between 150 and $300 \mathrm{mg} \cdot \mathrm{m}^{-2}$ in $20(31.7 \%)$, between 300 and $450 \mathrm{mg} / \mathrm{m}^{2}$ in $13(20.6 \%)$ patients, and $520 \mathrm{mg} \cdot \mathrm{m}^{-2}$ in $1(1.5 \%)$. No patient received more than $550 \mathrm{mg} \cdot \mathrm{m}^{-2}$.

\section{Echocardiographic Data}

Twenty-six (41\%) patients had at least one cardiac abnormality on echocardiogram. The most frequently detected abnormality was ESWS (range, 61-86 $\mathrm{g} \cdot \mathrm{cm}^{-2}$; median $66 \mathrm{~g} \cdot \mathrm{cm}^{-2}$; mean $\left.68.7 \mathrm{~g} \cdot \mathrm{cm}^{-2}\right)$ in 20 patients $(31.7 \%)$. The nine $(14 \%)$ patients who had abnormal shortening fractions (range, 23-28; median 26\%; mean $26 \%$ ) also had low EF (range 54-63, mean 60). Seven out of $63(11.1 \%$ ) had abnormal VCFc (range 0.76-0.9; median $0.84 \mathrm{c} \cdot \mathrm{sec}^{-1}$; mean $0.84 \mathrm{c} \cdot \mathrm{sec}^{-1}$ ) and 6 patients $(9.5 \%)$ had an abnormal stress velocity index. All three patients with clinical $\mathrm{CHF}$ had low FS; two had four abnormal parameters (FS, ESWS, VCFc, and SVI). Diastolic function (peak E/A velocities and their ratio) was normal in all patients, with the E/A ratios ranging from 1.33 to 3.05 , with a mean (SD) of $2.06 \pm 0.43$ (median 2.03). Baseline characteristics of the groups with normal and abnormal cardiac function are shown (Table I). The two groups were similar in the mean cumulative dose of AC received $\left(204.7 \pm 100.6 \mathrm{mg} \cdot \mathrm{m}^{-2}\right.$ abnormal cardiac function vs. $223.1 \pm 127.7 \mathrm{mg} \cdot \mathrm{m}^{-2}$ normal cardiac function, $P=0.54$ ) and interval post-AC treatment 
TABLE I. Clinical and Demographic Characteristics

\begin{tabular}{lccc}
\hline & $\begin{array}{c}\text { Normal } \\
\text { cardiac function }\end{array}$ & $\begin{array}{c}\text { Abnormal } \\
\text { cardiac function }\end{array}$ & $P$-value \\
\hline Male gender & $26 / 37(70 \%)$ & $11 / 26(42 \%)$ & 0.12 \\
Median age at time of diagnosis of cancer (years) & 7.1 & 5.7 & 0.74 \\
Median age at time of enrollment (years) & 12.1 & 14.3 & 0.96 \\
Median interval Post-AC-treatment (years) & 3.8 & 3.6 & 0.64 \\
Median cumulative anthracycline dose $\left(\mathrm{mg} \cdot \mathrm{m}^{-2}\right)$ & 165 & 180 & 0.54 \\
\hline
\end{tabular}

$(5.6 \pm 4.4$ years abnormal cardiac function and $5.1 \pm 3.7$ years normal cardiac function, $P=0.64)$.

Table II shows the number of patients with each cardiac abnormality as a function of the cumulative dose received. Age at treatment, interval of follow-up, and cumulative dose were not risk factors for cardiac dysfunction on multivariate analysis. At all doses, ESWS was the most frequently detected abnormality, present in 9 of $12(75 \%)$ at cumulative AC doses below $150 \mathrm{mg} \cdot \mathrm{m}^{-2}, 7$ of $10(70 \%)$ between 150 and $300 \mathrm{mg} \cdot \mathrm{m}^{-2}$, and all $4(100 \%)$ patients receiving $300-450 \mathrm{mg} \cdot \mathrm{m}^{-2}$. Twelve out of 29 patients $(40 \%)$ who had received cumulative doses below $150 \mathrm{mg} \cdot \mathrm{m}^{-2}$ had evidence of cardiac dysfunction, including 4 patients who had received doses as low as $90 \mathrm{mg} \cdot \mathrm{m}^{-2}$. The patient who received a cumulative dose of $520 \mathrm{mg} \cdot \mathrm{m}^{-2}$ had normal cardiac function after 12.4 years of follow-up.

\section{Plasma BNP}

The median BNP level for the cohort was $12.2 \mathrm{pg} \cdot \mathrm{dl}^{-1}$ (range, 5-117 pg. $\left.\mathrm{dl}^{-1}\right)$. Mean $( \pm \mathrm{SD})$ plasma BNP levels were significantly higher in the presence of abnormal cardiac function $\left(23.4 \pm 25.3 \mathrm{pg} \cdot \mathrm{dl}^{-1}, \quad \mathrm{n}=26\right.$ vs. $14.2 \pm 8.9 \mathrm{pg} \cdot \mathrm{dl}^{-1}, \mathrm{n}=37$ $P=0.02$; Fig. 1). Plasma BNP levels were higher when FS was low $(32.4 \pm 34.9(\mathrm{n}=9)$ vs. $15.6 \pm 12.4(\mathrm{n}=54), P<0.008)$. When all four systolic parameters were abnormal, plasma BNP was significantly higher than when one to three parameters were abnormal $(69.2 \pm 67.1(\mathrm{n}=2)$ vs. $19.6 \pm 17.3(\mathrm{n}=24), P<0.005)$. Plasma BNP levels in the five subjects on cardiac medications were significantly higher than the rest of the cohort $(49.8 \pm 40.2$ vs. $\left.15.2 \pm 11.9 \mathrm{pg} \cdot \mathrm{ml}^{-1}, P<0.001\right)$. When the five patients on medications were excluded, BNP levels remained significantly higher when cardiac function was abnormal than when function was normal (19.4 \pm 17.6 vs. $14.1 \pm 8.9, P=0.02)$. Table III depicts the mean plasma BNP levels in the subgroups with normal and abnormal function for each echocardiographic parameter. Plasma $\mathrm{BNP}$ was significantly higher in patients with abnormal FS, VCFc, and SVI, but not ESWS.

\section{DISCUSSION}

Among AC-treated patients, $41 \%$ had an abnormality of cardiac function at a mean follow-up interval of 5.2 years, the majority of whom were asymptomatic. Nine (14\%) patients had abnormal FS and EF, the commonly used clinical parameters. The most sensitive echo parameter for diagnosis of subclinical ACT was ESWS, representing $80 \%$ of cardiac abnormalities, while contractility by SVI was abnormal in only $24 \%$ of patients. Patients receiving doses as low as $90 \mathrm{mg} \cdot \mathrm{m}^{-2}$ had cardiac dysfunction. Plasma BNP was significantly higher in patients with cardiac dysfunction and when multiple echo parameters were abnormal. Plasma BNP was significantly elevated in the presence of abnormal contractility, although the elevation of BNP with increased ESWS did not reach statistical significance. These findings assume importance, given the growing numbers of $\mathrm{AC}$ treated patients and that $\mathrm{AC}$ use is mainly limited by cardiotoxicity [5-7,31].

Our finding of the association of an elevated BNP with late ACinduced cardiac dysfunction is similar to studies in adults, where a significant increase in plasma BNP has been noted in AC-treated patients with clinical or subclinical heart failure [32-34]. Previous data in children are limited. While one previous study reported elevation of plasma BNP $\left(29 \pm 31.2\right.$ vs. $\left.9 \pm 14.8 \mathrm{pg} \cdot \mathrm{ml}^{-1}\right)$ in patients with left ventricular dysfunction, compared to patients with normal function, another reported higher BNP levels in the ACtreated group as a whole, compared to untreated controls $\left(10.5 \pm 10.2\right.$ vs. $\left.4.09 \pm 2.2 \mathrm{pg} \cdot \mathrm{ml}^{-1}\right)[22,35]$. Both studies enrolled patients soon after completion of AC therapy when LV dysfunction could represent acute toxicity, which is not predictive of late ACT. Neither study excluded patients who had received chest radiation, which can worsen ACT. Moreover, VCFc, ESWS, and SVI were not utilized.

To our knowledge, ours is the largest study to evaluate plasma BNP for the detection of late ACT using sensitive echocardiographic indices. We believe our finding of a mild but significant elevation in plasma BNP with cardiac dysfunction is of clinical interest. Although largely asymptomatic, an increase in plasma BNP may

TABLE II. Effect of Cumulative AC Dose on Echocardiographic Parameters of Cardiac Function

\begin{tabular}{lcccccc}
\hline Dose/(n) & Any abnormality & Abnormal FS & Abnormal EF & Abnormal ESWS & Abnormal VCFc Abnormal SVI \\
\hline$<150 \mathrm{mg} \cdot \mathrm{m}^{-2}(29)$ & 12 & 3 & 3 & 9 & 3 & 2 \\
$150-300 \mathrm{mg} \cdot \mathrm{m}^{-2}(20)$ & 10 & 5 & 5 & 1 & 3 & 3 \\
$300-450 \mathrm{mg} \cdot \mathrm{m}^{-2}(13)$ & 4 & 1 & 0 & 0 & 1 & 1 \\
$>450 \mathrm{mg} \cdot \mathrm{m}^{-2}(1)$ & 0 & 0 & 9 & 20 & 0 & 7 \\
\hline
\end{tabular}




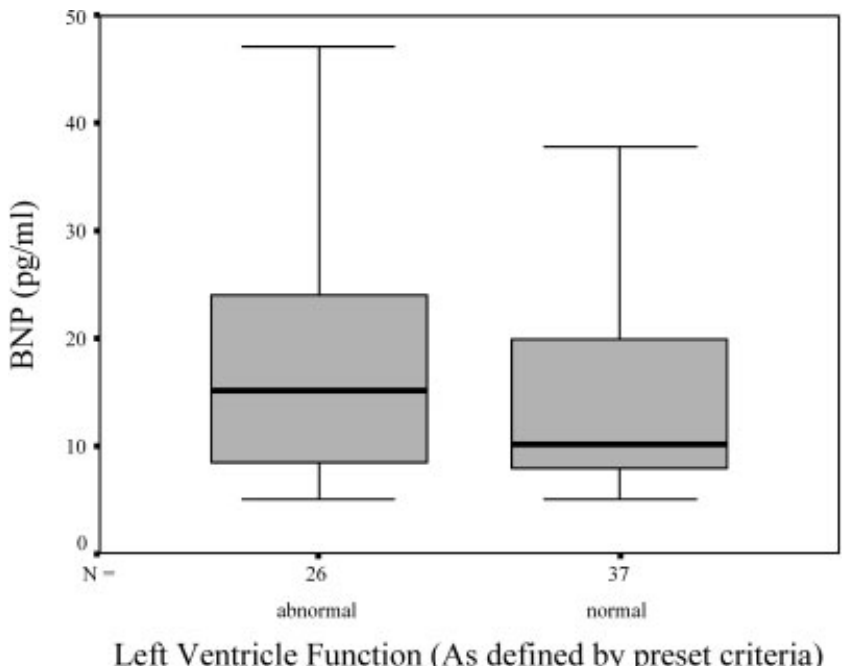

Fig. 1. Plasma BNP values in the groups with and without abnormal cardiac function as defined by specified criteria. The lower and upper bounds of the boxes indicate the 25th and 75th percentile values, respectively. The horizontal line indicates the median and the whisker bars represent the 10th and 90th percentiles.

be a biochemical surrogate for subtle but potentially progressive cardiac dysfunction. Indeed, the value of plasma BNP may lie in serial monitoring, where a change in plasma BNP may predict a decline in cardiac function for an individual patient. Further studies are needed to evaluate plasma BNP in this manner. We are currently conducting such a study.

A limitation of our study is that although plasma BNP was significantly higher from a statistical standpoint in patients with cardiac dysfunction, there was wide variation in the levels, precluding determination of a cut-off level with high sensitivity and specificity to discriminate between patients with normal cardiac function from those without. The overlap of BNP levels makes it unwise to use BNP as a sole screening method for ACT. BNP could not differentiate abnormal from normal ESWS in our study (mean BNP 23.5 abnormal vs. 15.4 normal ESWS). We suspect that our small sample size was not powered to detect differences in BNP in the subgroups for each individual echocardiographic parameter, which larger studies may uncover.

We also report the prevalence and characteristics of late cardiac dysfunction at curtailed AC doses, using sensitive echocardiographic parameters. Our observed prevalence of late cardiac abnormalities is similar to recent reports in which the mean cumulative AC doses were approximately $300 \mathrm{mg} \cdot \mathrm{m}^{-2}[9,36-39]$.

TABLE III. Plasma BNP in Groups With Normal and Abnormal Function for Each Echocardiographic Parameter

\begin{tabular}{lccc}
\hline & \multicolumn{2}{c}{ BNP (mean $\pm \mathrm{SD}) \mathrm{pg} \cdot \mathrm{ml}^{-1}$} & \\
\cline { 2 - 3 } & Abnormal function & Normal function & $P$-value \\
\hline FS & $32.4 \pm 34.9$ & $15.6 \pm 12.4$ & 0.009 \\
VCFS & $36.4 \pm 39.1$ & $15.6 \pm 12.4$ & 0.004 \\
ESWS & $23.5 \pm 27.5$ & $15.4 \pm 10.7$ & 0.09 \\
SVI & $32.3 \pm 41.7$ & $16.5 \pm 13.4$ & 0.04 \\
\hline
\end{tabular}

Our finding that even in the children who received cumulative doses below $150 \mathrm{mg} \cdot \mathrm{m}^{-2}, 40 \%$ had late cardiac dysfunction is novel and disturbing. We did not detect diastolic dysfunction in any of our patients, conflicting with some previous studies but consistent with others [40-42]. The established correlation between cumulative AC dose and cardiac dysfunction was not noted in our dataset, probably due to the small sample size.

Plasma BNP was significantly elevated in patients with late ACinduced cardiac dysfunction, although there was considerable overlap of levels in patients with normal and abnormal function. Serial measures of plasma BNP merit further evaluation for monitoring of AC-related cardiotoxicity. Even when treated with low cumulative AC doses, about $40 \%$ of AC-treated children had abnormal ventricular function.

\section{REFERENCES}

1. Hitchcock-Bryan S, Gelber R, Cassady JR, et al. The impact of induction anthracycline on long-term failure-free survival in childhood acute lymphoblastic leukemia. Med Pediatr Oncol 1986;14:211-215.

2. Fisher B, Redmond C, Wickerham DL, et al. Doxorubicincontaining regimens for the treatment of stage II breast cancer: The National Surgical Adjuvant Breast and Bowel Project experience. J Clin Oncol 1989;7:572-582.

3. Lipshultz SE, Colan SD, Gelber RD, et al. Late cardiac effects of doxorubicin therapy for acute lymphoblastic leukemia in childhood. N Engl J Med 1991;324:808-815.

4. Dorent R, Pavie A, Nataf P, et al. Heart transplantation is a valid therapeutic option for anthracycline cardiomyopathy. Transplant Proc 1995;27:1683.

5. Steinherz LJ, Steinherz PG, Tan CT, et al. Cardiac toxicity 4 to 20 years after completing anthracycline therapy. Jama 1991;266: $1672-1677$.

6. Lipshultz SE, Lipsitz SR, Sallan SE, et al. Chronic progressive cardiac dysfunction years after doxorubicin therapy for childhood acute lymphoblastic leukemia. J Clin Oncol 2005;23:26292636.

7. Kremer LC, van Dalen EC, Offringa M, et al. Anthracyclineinduced clinical heart failure in a cohort of 607 children: Long-term follow-up study. J Clin Oncol 2001;19:191-196.

8. Schwartz RG, McKenzie WB, Alexander J, et al. Congestive heart failure and left ventricular dysfunction complicating doxorubicin therapy. Seven-year experience using serial radionuclide angiocardiography. Am J Med 1987;82:1109-1118.

9. Sorensen K, Levitt GA, Bull C, et al. Late anthracycline cardiotoxicity after childhood cancer: A prospective longitudinal study. Cancer 2003;97:1991-1998.

10. Lipshultz SE, Rifai N, Dalton VM, et al. The effect of dexrazoxane on myocardial injury in doxorubicin-treated children with acute lymphoblastic leukemia. N Engl J Med 2004;351:145-153.

11. Lipshultz SE, Lipsitz SR, Sallan SE, et al. Long-term enalapril therapy for left ventricular dysfunction in doxorubicin-treated survivors of childhood cancer. J Clin Oncol 2002;20:4517-4522.

12. Steinherz LJ, Graham T, Hurwitz R, et al. Guidelines for cardiac monitoring of children during and after anthracycline therapy: Report of the Cardiology Committee of the Childrens Cancer Study Group. Pediatrics 1992;89:942-949.

13. Ross J, Jr. Afterload mismatch and preload reserve: A conceptual framework for the analysis of ventricular function. Prog Cardiovasc Dis 1976;18:255-264.

14. Borow KM, Neumann A, Marcus RH, et al. Effects of simultaneous alterations in preload and afterload on measurements of left ventricular contractility in patients with dilated cardiomyopathy: 
Comparisons of ejection phase, isovolumetric and end-systolic force-velocity indexes. J Am Coll Cardiol 1992;20:787-795.

15. Maeda K, Tsutamoto T, Wada A, et al. Plasma brain natriuretic peptide as a biochemical marker of high left ventricular enddiastolic pressure in patients with symptomatic left ventricular dysfunction. Am Heart J 1998;135:825-832.

16. Maisel AS. B-type natriuretic peptide (BNP) levels: Diagnostic and therapeutic potential. Rev Cardiovasc Med 2001;2:S13-18.

17. McCullough PA, Omland T, Maisel AS. B-type natriuretic peptides: A diagnostic breakthrough for clinicians. Rev Cardiovasc Med 2003;4:72-80.

18. Kunii Y, Kamada M, Ohtsuki S, et al. Plasma brain natriuretic peptide and the evaluation of volume overload in infants and children with congenital heart disease. Acta Med Okayama 2003; 57:191-197.

19. Koch A, Singer H. Normal values of B type natriuretic peptide in infants, children, and adolescents. Heart 2003;89:875-878.

20. Sanjeev S, Pettersen M, Lua J, et al. Role of plasma B-type natriuretic peptide in screening for hemodynamically significant patent ductus arteriosus in preterm neonates. J Perinatol 2005; 25:709-713.

21. Westerlind A, Wahlander $\mathrm{H}$, Lindstedt $\mathrm{G}$, et al. Clinical signs of heart failure are associated with increased levels of natriuretic peptide types B and A in children with congenital heart defects or cardiomyopathy. Acta Paediatr 2004;93:340-345.

22. Hayakawa H, Komada Y, Hirayama M, et al. Plasma levels of natriuretic peptides in relation to doxorubicin-induced cardiotoxicity and cardiac function in children with cancer. Med Pediatr Oncol 2001;37:4-9.

23. Gharib MI, Burnett AK. Chemotherapy-induced cardiotoxicity: Current practice and prospects of prophylaxis. Eur J Heart Fail 2002;4:235-242.

24. Gutgesell HP, Paquet M, Duff DF, et al. Evaluation of left ventricular size and function by echocardiography. Results in normal children. Circulation 1977;56:457-462.

25. Park MK. Noninvasive Techniques. In: Park MK, editor. Pediatric Cardiology for Practitioners. 4th edition. St. Louis: Mosby; 2002. pp 67-82.

26. Colan SD, Borow KM, Neumann A. Left ventricular end-systolic wall stress-velocity of fiber shortening relation: A load-independent index of myocardial contractility. J Am Coll Cardiol 1984;4: $715-724$.

27. Grossman W, Jones D, McLaurin LP. Wall stress and patterns of hypertrophy in the human left ventricle. J Clin Invest 1975;56:5664.

28. Colan SD, Parness IA, Spevak PJ, et al. Developmental modulation of myocardial mechanics: Age- and growth-related alterations in afterload and contractility. J Am Coll Cardiol 1992;19:619-629.
29. O’Leary PW, Durongpisitkul K, Cordes TM, et al. Diastolic ventricular function in children: A Doppler echocardiographic study establishing normal values and predictors of increased ventricular end-diastolic pressure. Mayo Clin Proc 1998;73:616628.

30. Yusuf S, W J, Probstfield J, Tyroler HA. Comparing Groups II. Multiple Testing Problem. In: Lang TA, Michells S, editors. How to report statistics in medicine annotated guideines for authors, editors, and reviewers. Philadelphia: BMJ Publishing Group; 1997. pp 81-92.

31. Von Hoff DD, Layard MW, Basa P, et al. Risk factors for doxorubicin-induced congestive heart failure. Ann Intern Med 1979;91:710-717.

32. Suzuki T, Hayashi D, Yamazaki T, et al. Elevated B-type natriuretic peptide levels after anthracycline administration. Am Heart J 1998; 136:362-363.

33. Okumura H, Iuchi K, Yoshida T, et al. Brain natriuretic peptide is a predictor of anthracycline-induced cardiotoxicity. Acta Haematol 2000;104:158-163.

34. Nousiainen T, Vanninen E, Jantunen E, et al. Natriuretic peptides during the development of doxorubicin-induced left ventricular diastolic dysfunction. J Intern Med 2002;251:228-234.

35. Pinarli FG, Oguz A, Tunaoglu FS, et al. Late cardiac evaluation of children with solid tumors after anthracycline chemotherapy. Pediatr Blood Cancer 2005;44:370-377.

36. Lipshultz SE, Lipsitz SR, Mone SM, et al. Female sex and drug dose as risk factors for late cardiotoxic effects of doxorubicin therapy for childhood cancer. N Engl J Med 1995;332:17381743.

37. Sorensen K, Levitt G, Sebag-Montefiore D, et al. Cardiac function in Wilms' tumor survivors. J Clin Oncol 1995;13:1546-1556.

38. Sorensen K, Levitt G, Bull C, et al. Anthracycline dose in childhood acute lymphoblastic leukemia: Issues of early survival versus late cardiotoxicity. J Clin Oncol 1997;15:61-68.

39. Pihkala J, Saarinen UM, Lundstrom U, et al. Myocardial function in children and adolescents after therapy with anthracyclines and chest irradiation. Eur J Cancer 1996;32A:97-103.

40. Marchandise B, Schroeder E, Bosly A, et al. Early detection of doxorubicin cardiotoxicity: Interest of Doppler echocardiographic analysis of left ventricular filling dynamics. Am Heart J 1989; 118:92-98.

41. Stoddard MF, Seeger J, Liddell NE, et al. Prolongation of isovolumetric relaxation time as assessed by Doppler echocardiography predicts doxorubicin-induced systolic dysfunction in humans. J Am Coll Cardiol 1992;20:62-69.

42. Schmitt K, Tulzer G, Merl M, et al. Early detection of doxorubicin and daunorubicin cardiotoxicity by echocardiography: Diastolic versus systolic parameters. Eur J Pediatr 1995;154:201-204. 